\title{
Physicochemical properties of some pyrimidine derivatives in some organic solvents
}

\begin{abstract}
Some physicochemical parameters such as density, refractive index and conductance of some newly synthesized pyrimidine derivatives have been measured in N, N-dimethyl formamide, chloroform and methanol at $308.15 \mathrm{~K}$. It is observed that these studied parameters depend on the solvent and structure of compounds, which may be due to different type of interactions.

Keywords: density, refractive index, conductance, methanol, N, N-dimethyl formamide, chloroform
\end{abstract}

Volume 7 Issue 5 - 2018

Shipra Baluja, Asmita Hirapara, Divyata Lava

Department of Chemistry, Saurashtra University, India

Correspondence: Shipra Baluja, Department of Chemistry, Saurashtra University, Rajkot-360005 (India), Tel +9l9687692918,Email Shipra_baluja@rediffmail.com

Received: July 30, 2017 | Published: September 14, 2018

\section{Introduction}

Heterocyclic compounds play an immense role in many biochemical processes ${ }^{1}$ and numerous heterocyclic compounds are biosynthesized by plants and animals, which are also associated to significant biological properties. Nitrogen containing heterocyclic compounds are known to play an essential role in many living systems. The nucleic acid bases are the derivatives of pyrimidine and purine, ${ }^{2}$ found in RNA and DNA in the form of uracil, thymine, cytosine, adenine and guanine. These nitrogen containing heterocycles are synthetically challenging models for a number of physiologically active natural products. ${ }^{3}$

Pyrimidines are always an attraction point for researchers due to their pharmacological usages. These compounds are known to possess wide spectrum of biological activities such as anti-tubercular, anti-HIV, anti-microbial, anti-analgesic, anti-inflammatory and antimalarial, antidepressant, anticonvulsant, antioxidant, anticancer, antifungal, etc. ${ }^{4-16}$.

Thus, due to these biologically activity of pyrimidines, in the present paper, different pyrimidines compounds i.e., tetrahydropyrimidines and 2, 4-disubstituted pyrimidines have been synthesized. Some physicochemical properties such as density, refractive index and conductance of solutions of these synthesized compounds have been studied in different solvents at $308.15 \mathrm{~K}$.

\section{Experimental}

Some new tetrahydropyrimidines and 2, 4-disubstituted pyrimidines compounds have been synthesized. The general structures and substitutions in different compounds are given in Figure 1.<smiles>N#Cc1c(N)nc(S)nc1C1#[R]=CC=C1</smiles>

Where $\mathrm{R}$ is : SNS-I: 4-OH, 3-OCH $-\mathrm{C}_{6} \mathrm{H}_{4} ; \mathrm{SNS}-2: 4-\mathrm{OCH}_{3}-\mathrm{C}_{6} \mathrm{H}_{4} ; \mathrm{SNS}-3$ : 4-OH-C $\mathrm{C}_{6} \mathrm{H}_{4}$; SNS-4: 4-Cl- $\mathrm{C}_{6} \mathrm{H}_{4}$; $\mathrm{SNS}-5$ : 3-Cl- $\mathrm{C}_{6} \mathrm{H}_{4}$; SNS-6: 4-F- $\mathrm{C}_{6} \mathrm{H}_{4}$; SNS-7: 3-NO $-\mathrm{NO}_{6} \mathrm{H}_{4}$; SNS-8: $-\mathrm{C}_{6} \mathrm{H}_{5}$; SNS-9: $\mathrm{C}_{4} \mathrm{H}_{3} \mathrm{O}$; SNS- $\mathrm{IO}:-\mathrm{CH}=\mathrm{CH}-\mathrm{C}_{6} \mathrm{H}_{5}$;

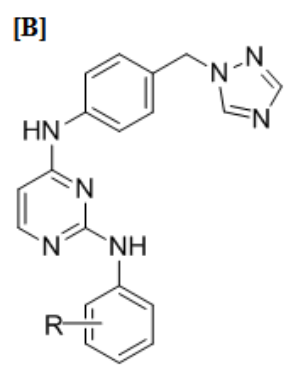

Where $\mathrm{R}$ is: $\mathrm{SDN}-\mathrm{I}$ : 4-Cl; SDN-2: 4- $\mathrm{CH}_{3}$; $\mathrm{SDN}-3$ : 4-F; SDN-4: 3-CF 3 ; $\mathrm{SDN}-5$ : 3-Cl, 4-F;<smiles>[R]c1ccccc1Nc1nccc(Oc2cccc3ccccc23)n1</smiles>

Where R is: SDO-I: 4-Cl; SDO-2: 4- $\mathrm{CH}_{3}$; SDO-3: 4-F; SDO-4: 3-CF ${ }_{3}$ SDO-5: 3-Cl, 4-F.

Figure I General structure of synthesized different pyrimidine derivatives: [A] tetrahydropyrimidines (SNS series); [B] 2, 4-disubstituted pyrimidines (SDN series) and [C] 2, 4-disubstituted pyrimidines (SDO series)

\section{Physicochemical studies}

The solvents DMF, chloroform and methanol used for physicochemical studies were purified by fractionally distillation by the reported method. ${ }^{17}$ For each compound, a series of solutions of different concentrations were prepared in these solvents. The choice of different solvents for different compounds is due to solubility problem.

The density and refractive index of pure solvents and solutions 
were measured by using pycnometer and Abbe refractometer respectively at $308.15 \mathrm{~K}$. The desired temperature was maintained by circulating water through jacket around the prisms of refractometer from an electronically controlled thermostatic water bath (NOVA NV$8550 \mathrm{E})$. The uncertainty of temperature was $\pm 0.1^{\circ} \mathrm{C}$.

The conductance of each solution was measured by using Elico Conductivity Meter (Model No. CM 180) at 308.15K. The measured conductance was corrected by subtracting the conductance of pure solvent.

\section{Results and discussion \\ Density and refractive index}

Table 1 shows the experimental values of densities and refractive index for all the studied solutions. Using experimental density of solution, density of each compound was calculated using the following relation:

$$
\frac{1}{\rho_{12}}=\frac{g_{1}}{\rho_{1}}+\frac{g_{2}}{\rho_{2}}
$$

Table I The density $\left(\rho_{12}\right)$ and refractive index $(n)$ of synthesized compounds at $308.15 \mathrm{~K}$

\begin{tabular}{|c|c|c|c|c|}
\hline Conc. M & $\rho_{12}$ g.cm $\mathrm{cm}^{-3}$ & $\mathbf{n}$ & $\rho_{12} \mathrm{~g} \cdot \mathrm{cm}^{-3}$ & $\mathbf{N}$ \\
\hline \multicolumn{5}{|c|}{ Tetrahydropyrimidines } \\
\hline & DMF & \multicolumn{3}{|c|}{ Chloroform } \\
\hline \multicolumn{5}{|l|}{ SNS-I } \\
\hline 0.00 & 0.9338 & 1.4239 & 1.4713 & 1.4397 \\
\hline 0.01 & 0.9456 & 1.4231 & 1.4715 & 1.4402 \\
\hline 0.02 & 0.9465 & 1.4239 & 1.4718 & 1.4410 \\
\hline 0.04 & 0.9483 & 1.4247 & 1.4721 & 1.4421 \\
\hline 0.06 & 0.9500 & 1.4255 & 1.4726 & 1.4433 \\
\hline 0.08 & 0.9516 & 1.4265 & 1.4731 & 1.4448 \\
\hline 0.10 & 0.9535 & 1.4273 & 1.4737 & 1.4458 \\
\hline \multicolumn{5}{|l|}{ SNS-2 } \\
\hline 0.01 & 0.9448 & 1.4223 & 1.4717 & 1.4399 \\
\hline 0.02 & 0.9452 & 1.4229 & 1.4724 & 1.4404 \\
\hline 0.04 & 0.9461 & 1.4238 & 1.4736 & 1.4414 \\
\hline 0.06 & 0.9470 & 1.4248 & 1.4749 & 1.4423 \\
\hline 0.08 & 0.9479 & 1.4259 & 1.4761 & 1.4433 \\
\hline 0.10 & 0.9489 & 1.4268 & 1.4774 & 1.4443 \\
\hline \multicolumn{5}{|l|}{ SNS-3 } \\
\hline 0.01 & 0.9486 & 1.4212 & 1.4714 & 1.4400 \\
\hline 0.02 & 0.9489 & 1.4228 & 1.4718 & 1.4406 \\
\hline 0.04 & 0.9495 & 1.4230 & 1.4727 & 1.4417 \\
\hline 0.06 & 0.9501 & 1.4242 & 1.4736 & 1.4428 \\
\hline 0.08 & 0.9507 & 1.4252 & 1.4745 & 1.4440 \\
\hline 0.10 & 0.9513 & 1.4263 & 1.4754 & 1.4450 \\
\hline \multicolumn{5}{|l|}{ SNS-4 } \\
\hline 0.01 & 0.9494 & 1.4219 & 1.4749 & 1.4415 \\
\hline
\end{tabular}

Table Continued....

\begin{tabular}{|c|c|c|c|c|}
\hline 0.02 & 0.9503 & 1.4223 & 1.4753 & 1.4416 \\
\hline 0.04 & 0.9520 & $\mid .4231$ & $1.476 \mathrm{I}$ & 1.4420 \\
\hline 0.06 & 0.9538 & 1.4239 & 1.4768 & 1.4423 \\
\hline 0.08 & 0.9555 & 1.4250 & I.4776 & 1.4425 \\
\hline 0.10 & 0.9573 & I.4255 & I.4784 & 1.4428 \\
\hline \multicolumn{5}{|c|}{ SNS-5 } \\
\hline 0.01 & 0.9494 & 1.4203 & 1.4720 & 1.4409 \\
\hline 0.02 & 0.9503 & 1.4208 & I.4723 & 1.4410 \\
\hline 0.04 & 0.9520 & 1.4217 & 1.4730 & 1.4413 \\
\hline 0.06 & 0.9538 & 1.4226 & 1.4736 & 1.4416 \\
\hline 0.08 & 0.9556 & 1.4235 & I.4743 & 1.4418 \\
\hline 0.10 & 0.9573 & I.4244 & I.4750 & I.442I \\
\hline \multicolumn{5}{|c|}{ SNS-6 } \\
\hline 0.01 & 0.9454 & $1.421 \mathrm{I}$ & I.4747 & 1.4412 \\
\hline 0.02 & 0.9458 & 1.4215 & I. 4752 & 1.4414 \\
\hline 0.04 & 0.9467 & I.4222 & 1.4762 & 1.4418 \\
\hline 0.06 & 0.9476 & 1.4230 & $\mathrm{I} .4772$ & 1.4425 \\
\hline 0.08 & 0.9484 & I.4237 & I.4782 & 1.4426 \\
\hline 0.10 & 0.9494 & I.4244 & I.4792 & 1.4430 \\
\hline \multicolumn{5}{|c|}{ SNS-7 } \\
\hline 0.01 & 0.9529 & 1.4191 & I. 4800 & 1.4408 \\
\hline 0.02 & 0.9530 & 1.4200 & $\mathrm{I} .480 \mathrm{I}$ & 1.4412 \\
\hline 0.04 & 0.9531 & 1.4217 & 1.4803 & 1.4420 \\
\hline 0.06 & 0.9535 & 1.4234 & 1.4805 & 1.4426 \\
\hline 0.08 & 0.9537 & I.4252 & I.4807 & 1.4433 \\
\hline 0.10 & 0.9540 & 1.4269 & 1.4809 & 1.4440 \\
\hline \multicolumn{5}{|c|}{ SNS-8 } \\
\hline 0.01 & 0.9506 & 1.4225 & 1.4735 & 1.4408 \\
\hline 0.02 & 0.9517 & 1.4228 & I.4737 & $|.44| I$ \\
\hline 0.04 & 0.9528 & 1.4234 & I.474I & 1.4416 \\
\hline 0.06 & 0.9531 & 1.4239 & I.4744 & I.442I \\
\hline 0.08 & 0.9547 & 1.4245 & I.4748 & 1.4426 \\
\hline 0.10 & $0.955 I$ & $\mid .425 \mathrm{I}$ & I.475I & I.443| \\
\hline \multicolumn{5}{|c|}{ SNS-9 } \\
\hline 0.01 & 0.9424 & 1.4164 & 1.4809 & 1.4397 \\
\hline 0.02 & 0.9429 & 1.4175 & 1.4813 & 1.4400 \\
\hline 0.04 & 0.9440 & 1.4195 & 1.4820 & 1.4406 \\
\hline 0.06 & $0.945 I$ & 1.4214 & 1.4827 & 1.4412 \\
\hline 0.08 & 0.9462 & I. 4234 & $\mathrm{I} .4834$ & 1.4418 \\
\hline 0.10 & 0.9473 & 1.4253 & $|.474|$ & 1.4424 \\
\hline \multicolumn{5}{|c|}{ SNS-IO } \\
\hline 0.01 & 0.9562 & 1.4233 & 1.4746 & 1.4396 \\
\hline 0.02 & 0.9565 & 1.4238 & 1.4751 & 1.4398 \\
\hline 0.04 & $0.957 \mid$ & 1.4244 & 1.4763 & 1.4399 \\
\hline 0.06 & 0.9576 & 1.4251 & 1.4775 & 1.4401 \\
\hline 0.08 & $0.958 \mid$ & 1.4257 & |. 4787 & 1.4402 \\
\hline
\end{tabular}


Table Continued....

\begin{tabular}{|c|c|c|c|c|c|c|c|c|c|}
\hline \multirow{2}{*}{\multicolumn{3}{|c|}{$\begin{array}{lll}0.10 & 0.9587 & 1.4262 \\
\text { 2, 4-disubstituted pyrimidines }\end{array}$}} & 1.4798 & 1.4404 & 0.10 & 0.9529 & 1.4320 & 0.7894 & 1.3305 \\
\hline & & & & & \multicolumn{5}{|c|}{ SDO-2 } \\
\hline & \multicolumn{2}{|l|}{ DMF } & \multicolumn{2}{|c|}{ Methanol } & 0.01 & 0.9422 & 1.4240 & 0.7793 & 1.3260 \\
\hline SDN-I & & & & & 0.02 & 0.9434 & 1.4245 & 0.7809 & 1.3270 \\
\hline 0.00 & 0.9338 & 1.4239 & 0.7770 & 1.3250 & 0.04 & 0.9449 & 1.4255 & 0.7831 & 1.3275 \\
\hline 0.01 & 0.9432 & 1.4245 & 0.7794 & 1.3260 & 0.06 & 0.9488 & 1.4265 & 0.7857 & 1.3285 \\
\hline 0.02 & 0.9446 & 1.4255 & 0.7812 & 1.3265 & 0.08 & 0.9502 & 1.4280 & 0.7872 & 1.3294 \\
\hline 0.04 & 0.9468 & 1.4270 & 0.7839 & 1.3295 & 0.10 & 0.9513 & 1.4295 & 0.7912 & 1.3315 \\
\hline 0.06 & 0.9484 & 1.4285 & 0.7879 & 1.3310 & SDO- & & & & \\
\hline 0.08 & 0.9497 & 1.4295 & 0.7892 & 1.3325 & 0.01 & 0.9428 & 1.4240 & 0.7795 & 1.3260 \\
\hline 0.10 & 0.9516 & 1.4310 & 0.7909 & 1.3330 & 0.02 & 0.9447 & 1.4245 & 0.7809 & 1.3275 \\
\hline SDN-2 & & & & & 0.04 & 0.9461 & 1.4255 & 0.7829 & 1.3290 \\
\hline 0.01 & 0.9430 & 1.4240 & 0.7816 & 1.3265 & 0.06 & 0.9496 & 1.4260 & 0.7855 & 1.3305 \\
\hline 0.02 & $0.944 I$ & 1.4245 & 0.7839 & 1.3280 & 0.08 & 0.9520 & 1.4270 & 0.7876 & 1.3315 \\
\hline 0.04 & 0.9462 & 1.4260 & 0.7880 & 1.3300 & 0.10 & 0.9535 & 1.4281 & 0.7914 & 1.3335 \\
\hline 0.06 & 0.9479 & 1.4270 & 0.7915 & 1.3315 & SDO- & & & & \\
\hline 0.08 & 0.9491 & 1.4285 & 0.7948 & 1.3330 & 0.01 & 0.9429 & 1.4240 & 0.7801 & 1.3265 \\
\hline 0.10 & 0.9504 & 1.4300 & 0.7997 & 1.3345 & 0.02 & 0.9452 & 1.4245 & 0.7824 & 1.3260 \\
\hline SDN-3 & & & & & 0.04 & 0.947 I & 1.4255 & 0.7864 & 1.3270 \\
\hline 0.01 & 0.9428 & 1.4250 & 0.7804 & 1.3280 & 0.06 & 0.9489 & 1.4270 & 0.7898 & 1.3280 \\
\hline 0.02 & 0.9438 & 1.4260 & 0.7819 & 1.3295 & 0.08 & 0.9507 & 1.4285 & 0.7923 & 1.3295 \\
\hline 0.04 & 0.9455 & 1.4275 & 0.7837 & 1.3315 & 0.10 & 0.9530 & 1.4295 & 0.7950 & 1.3330 \\
\hline 0.06 & 0.9474 & 1.4295 & 0.7869 & 1.3330 & SDO & & & & \\
\hline 0.08 & 0.9489 & 1.4310 & 0.7883 & 1.3345 & 0.01 & 0.9431 & 1.4245 & 0.7797 & 1.3260 \\
\hline 0.10 & 0.9501 & 1.4320 & 0.7893 & 1.3360 & 0.02 & 0.9449 & 1.4265 & $0.78 \mid 4$ & 1.3275 \\
\hline SDN-4 & & & & & 0.04 & 0.9468 & 1.4290 & 0.7844 & 1.3285 \\
\hline 0.01 & 0.9434 & 1.4250 & 0.7830 & 1.3265 & 0.06 & 0.9495 & 1.4315 & 0.7869 & 1.3295 \\
\hline 0.02 & 0.9447 & 1.4265 & $0.785 I$ & 1.3285 & 0.08 & 0.9520 & 1.4325 & 0.7885 & 1.3305 \\
\hline 0.04 & 0.9474 & 1.4285 & 0.7883 & 1.3310 & 0.10 & 0.9540 & 1.4340 & 0.7923 & 1.3315 \\
\hline
\end{tabular}

where $\rho_{12}$ is the density of solution and $\rho_{1}$ and $\rho_{2}$ are the densities of solvent and solute respectively. $g_{1}$ and $g_{2}$ are the weight fractions of solvent and solute.

The evaluated densities of all the compounds are listed in Table 2 along with the theoretical densities, which were calculated using the following equation: ${ }^{18}$

$$
\rho=K M / N_{A} \sum \Delta V_{i}
$$

where $\rho$ is the density of the compound, $K$ is packing fraction (0.599), $\mathrm{M}$ is the molecular weight of the compound, $N_{A}$ is the Avogadro's number and $\Delta V_{i}$ is the volume increment of the atoms and atomic groups present in the compound.

Comparison of densities values showed that theoretical density values are different from those evaluated from experimental data. Further, for the same compound, density in the two solvents is different. This suggests that solvent plays an important role. In solutions, compounds interact differently depending upon their substitution, structure and nature of solvent. These molecular interactions affect volume, which causes change in density.

Further, the molar refraction of a pure liquid $(M R D)_{1}$, were calculated by the following equation: 


$$
(M R D)_{1}=\left[\frac{n^{2}-1}{n^{2}+1}\right] \frac{M}{\rho}
$$

where $n, M$ and $\rho$ are refractive index, molecular weight and density pure liquid respectively.

Table 2 Experimental and theoretical densities of compounds at 308.15K

\begin{tabular}{llll} 
Compounds & \multicolumn{2}{l}{$\begin{array}{l}\text { Experimental density } \\
\text { g.cm }\end{array}$} & $\begin{array}{l}\text { Theoretical density } \\
\text { g.cm }\end{array}$ \\
\hline SNS-1 & DMF & Chloroform & \\
SNS-2 & 1.5175 & 1.6234 & 1.2960 \\
SNS-3 & 1.2270 & 1.9380 & 1.2624 \\
SNS-4 & 1.2870 & 1.7825 & 1.3163 \\
SNS-5 & 1.7953 & 1.8692 & 1.3565 \\
SNS-6 & 1.7699 & 1.6978 & 1.3565 \\
SNS-7 & 1.2610 & 2.0121 & 1.3351 \\
SNS-8 & 1.2438 & 1.8519 & 1.3664 \\
SNS-9 & 1.2315 & 1.6892 & 1.2787 \\
SNS-10 & 1.2642 & 2.4213 & 1.5300 \\
& 1.5974 & 2.0661 & 1.3877 \\
SDN-I & 1.2804 & 1.2484 & 1.3612 \\
SDN-2 & 1.2531 & 1.9417 & 1.2766 \\
SDN-3 & 1.3405 & 1.1628 & 1.3485 \\
SDN-4 & 1.3605 & 1.3680 & 1.6028 \\
SDN-5 & 1.3021 & 1.4599 & 1.4420 \\
SDO-I & 1.4368 & 1.1919 & 1.1947 \\
SDO-2 & 1.3870 & 1.3123 & 1.1177 \\
SDO-3 & 1.4306 & 1.7007 & 1.1787 \\
SDO-4 & 1.3228 & 1.2063 & 1.3514 \\
SDO-5 & 1.4225 & 1.2887 & 1.2192 \\
\hline
\end{tabular}

For solutions, the following equation was used to determining molar refraction:

$$
(M R D)_{12}=\left[\frac{n_{12}^{2}-1}{n_{12}^{2}+1}\right]\left[\frac{X_{1} M_{1}+X_{2} M_{2}}{\rho_{12}}\right]
$$

where $n_{12}$ and $\rho_{12}$ are refractive index and density of solution respectively. $X_{1}$ and $X_{2}$ are the mole fractions and $M_{1}$ and $M_{2}$ are the molecular weight of the solvent and solute respectively.

From the values of the molar refraction of solution and pure solvent, molar refraction of solid compounds were determined by following equation:

$$
(M R D)_{12}=X_{1}(M R D)_{1}+X_{2}(M R D)_{2}
$$

From the density and molar refraction data, the refractive indexes of all the compounds were calculated from eq. (5). The molar refraction $(M R D)$, and refractive index of all the compounds are reported in Table 3 for $0.1 \mathrm{M}$ solution.

It is evident from Table 3 that both (MRD), and refractive index of compounds are different in each solvent. This again proves that in different solvents, intermolecular interactions are different, which affect these parameters. In some solvents, there may be interaction between solute and solvent molecules where as in others breakage of bonds may take place. As refractive index and molar refraction depends upon not only atomic refraction but also upon single, double or triple bonds, the type of interactions taking place in solution affects these parameters. Further, bond polarity also causes change in molar refraction. Thus, type of solvent affects the refractive index and molar refraction of a solute.

\begin{tabular}{|c|c|c|c|c|}
\hline Compounds & $\left(M_{R} D_{2}\right)$ & $n$ & $\left(M R D_{2}\right)$ & $N$ \\
\hline \multicolumn{5}{|l|}{ Solvents } \\
\hline & \multicolumn{2}{|l|}{ DMF } & \multicolumn{2}{|c|}{ Chloroform } \\
\hline SNS-I & 121.62 & 1.7680 & 76.53 & 1.4703 \\
\hline SNS-2 & $|27.0|$ & 1.6448 & 59.26 & 1.4469 \\
\hline SNS-3 & 114.30 & 1.5263 & 64.01 & 1.3921 \\
\hline SNS-4 & 99.00 & 1.7553 & 50.46 & 1.3539 \\
\hline SNS-5 & 94.42 & 1.7361 & 53.75 & 1.3576 \\
\hline SNS-6 & 109.83 & 1.5803 & 47.02 & 1.3722 \\
\hline SNS-7 & $|19.4|$ & 1.5820 & 54.05 & 1.3677 \\
\hline SNS-8 & 104.12 & 1.5317 & 51.63 & 1.3419 \\
\hline SNS-9 & 112.69 & 1.6026 & 30.06 & 1.2799 \\
\hline \multirow[t]{2}{*}{ SNS-10 } & 96.77 & 1.6999 & 33.79 & 1.2784 \\
\hline & DMF & & \multicolumn{2}{|l|}{ Methanol } \\
\hline SDN-I & 116.23 & 1.7175 & 107.01 & 1.6251 \\
\hline SDN-2 & 108.67 & 1.6872 & 87.16 & 1.9230 \\
\hline SDN-3 & 121.28 & 1.8583 & 124.15 & 1.7308 \\
\hline SDN-4 & 126.43 & 1.7764 & 128.42 & 1.7989 \\
\hline SDN-5 & 121.29 & 1.7296 & 141.56 & 2.0683 \\
\hline SDO-I & 109.87 & 1.8569 & 88.87 & 1.5211 \\
\hline SDO-2 & 95.38 & 1.7731 & 84.56 & 1.5932 \\
\hline SDO-3 & 82.26 & 1.6053 & 86.98 & 1.8493 \\
\hline SDO-4 & 122.39 & 1.9435 & 106.60 & 1.5894 \\
\hline SDO-5 & 105.28 & 1.6510 & 91.59 & 1.5586 \\
\hline
\end{tabular}

Table 3 Molar refraction (MRD) ${ }_{2}$ and refractive index $(n)$ of $0.1 \mathrm{M}$ solutions of compounds at $308.15 \mathrm{~K}$

\section{Conductance}

The measured conductance $(k)$ of each solution after correction are given in Table 4. It is observed that for all the studied compounds, conductance increases with concentration in all the solvents. The conductance measurement of two tetrahydropyrimidine compounds SNS-1 and SNS-3 cannot be done as these compounds had very less solubility in chloroform. For both tetrahydropyrimidines 2, 4-disubstituted pyrimidine compounds, conductance is lower in DMF than that in chloroform and methanol respectively.

From corrected conductance, specific conductance $(\kappa)$ and equivalent conductance $\left(\lambda_{c}\right)$ are calculated using the following equations:

$$
\begin{gathered}
\kappa=k \theta \\
\lambda_{c}=1000 \frac{\kappa}{C}
\end{gathered}
$$

where $\theta$ is the cell constant $\left(0.96 \mathrm{~cm}^{-1}\right)$ and $c$ is the concentration (g.equi./lit.) of solution. 
Table 4 The conductance $(k)$ of synthesized compounds in different solvents at $308.15 \mathrm{~K}$

$$
\text { Conc. }
$$

M

\section{k $10^{4} \mathrm{mho}$}

Tetrahydropyrimidines

DMF

\begin{tabular}{|c|c|c|c|c|c|c|c|c|c|c|}
\hline & SNS - I & SNS -2 & SNS - 3 & SNS -4 & SNS -5 & SNS -6 & SNS -7 & SNS -8 & SNS -9 & SNS - I0 \\
\hline 0.000 & 0.2800 & 0.2800 & 0.2800 & 0.2800 & 0.2800 & 0.2800 & 0.2800 & 0.2800 & 0.2800 & 0.2800 \\
\hline 0.001 & 0.0187 & 0.0174 & 0.0017 & 0.0089 & 0.0050 & 0.0017 & 0.0013 & 0.0122 & 0.0030 & 0.0209 \\
\hline 0.002 & 0.0370 & 0.0346 & 0.0034 & 0.0169 & 0.0094 & 0.0028 & 0.0021 & 0.0238 & 0.0059 & $0.04 \mid 4$ \\
\hline 0.004 & 0.0728 & 0.0684 & 0.0064 & 0.0326 & 0.0170 & 0.0057 & 0.0040 & 0.0454 & 0.0115 & 0.0804 \\
\hline 0.006 & 0.1062 & 0.0988 & 0.0094 & 0.0463 & 0.0243 & 0.0077 & 0.0053 & 0.0660 & 0.0165 & 0.1140 \\
\hline 0.008 & 0.1336 & 0.1284 & 0.0111 & 0.0580 & 0.0295 & 0.0088 & $0.005 \mathrm{I}$ & 0.0843 & 0.0184 & 0.1424 \\
\hline 0.010 & 0.1420 & 0.1526 & 0.0075 & 0.0675 & 0.0306 & 0.0100 & 0.0043 & 0.1000 & 0.0190 & 0.1550 \\
\hline 0.020 & 0.1979 & 0.2453 & 0.0279 & 0.1121 & 0.0494 & 0.0291 & 0.0106 & 0.1421 & 0.0352 & 0.2467 \\
\hline 0.040 & 0.2246 & 0.3684 & 0.0470 & 0.2020 & 0.0730 & 0.0684 & 0.0198 & 0.1876 & 0.0620 & 0.3206 \\
\hline 0.060 & 0.2495 & 0.4080 & 0.1009 & 0.2735 & 0.0726 & 0.0996 & 0.0178 & 0.2331 & 0.0720 & 0.3947 \\
\hline 0.080 & 0.2738 & 0.3449 & 0.1258 & 0.3459 & 0.0746 & 0.1299 & 0.0176 & 0.2779 & 0.0756 & 0.4689 \\
\hline 0.100 & 0.2992 & 0.2707 & 0.1595 & 0.4185 & 0.0709 & 0.1586 & 0.0107 & $0.324 I$ & 0.0783 & 0.5431 \\
\hline \multicolumn{11}{|c|}{ Chloroform } \\
\hline 0.000 & 0.084 & 0.084 & 0.084 & 0.084 & 0.084 & 0.084 & 0.084 & 0.084 & 0.084 & 0.084 \\
\hline 0.001 & - & 0.0890 & - & 0.0890 & 0.0850 & 0.1000 & 0.1050 & 0.1038 & 0.1246 & 0.1187 \\
\hline 0.002 & - & 0.1740 & - & 0.1558 & 0.1335 & 0.1880 & 0.1860 & 0.2003 & 0.2373 & 0.2225 \\
\hline 0.004 & - & 0.3400 & - & 0.2967 & 0.2373 & 0.3560 & 0.3227 & 0.3560 & 0.4450 & 0.4050 \\
\hline 0.006 & - & 0.4980 & - & 0.3900 & 0.3120 & 0.4680 & 0.4160 & 0.4800 & 0.6000 & 0.5680 \\
\hline 0.008 & - & 0.6240 & - & 0.5200 & 0.3740 & 0.5280 & 0.5020 & 0.5512 & 0.7390 & 0.6760 \\
\hline 0.010 & - & 0.6400 & - & 0.4450 & 0.4020 & 0.5500 & 0.5120 & 0.5680 & 0.8460 & 0.7400 \\
\hline 0.020 & - & 0.8900 & - & 0.7000 & 0.6230 & 0.8900 & 0.7120 & 1.0680 & 1.2460 & I.1570 \\
\hline 0.040 & - & 0.9790 & - & 0.8010 & 0.6230 & 0.8900 & 0.8010 & 1.2460 & 1.7350 & 1.6460 \\
\hline 0.060 & - & 0.9790 & - & 0.8900 & $0.7 \mid 20$ & 0.9790 & 0.8900 & 1.3350 & 1.9350 & 1.8000 \\
\hline 0.080 & - & 1.0680 & - & 0.8900 & $0.7 \mid 20$ & 0.9790 & 0.9790 & 1.4240 & 2.0640 & 1.6800 \\
\hline 0.100 & - & 1.0680 & - & 0.9790 & 0.8010 & 0.9790 & I.1570 & 1.6020 & 1.9900 & 1.5130 \\
\hline
\end{tabular}

2,4-Disubstituted pyrimidines

DMF

\section{$\begin{array}{lllllllll}\text { SDN-I } & \text { SDN -2 } & \text { SDN -3 } & \text { SDN -4 } & \text { SDN -5 } & \text { SDO - I } & \text { SDO-2 } & \text { SDO-3 } & \text { SDO-4 }\end{array}$}

$\begin{array}{lllllllllll}\mathbf{0 . 0 0 0} & 0.2800 & 0.2800 & 0.2800 & 0.2800 & 0.2800 & 0.2800 & 0.2800 & 0.2800 & 0.2800 & 0.2800 \\ \mathbf{0 . 0 0 1} & 0.0735 & 0.2037 & 0.1200 & 0.1851 & 0.0828 & 0.0642 & 0.1107 & 0.2967 & 0.185 I & 0.2595 \\ \mathbf{0 . 0 0 2} & 0.2130 & 0.3525 & 0.2874 & 0.3060 & 0.2316 & 0.2781 & 0.3339 & 0.5757 & 0.4827 & 0.5850 \\ \mathbf{0 . 0 0 4} & 0.4362 & 0.6780 & 0.5943 & 0.5385 & 0.4362 & 0.6687 & 0.6780 & 1.0221 & 1.0128 & 1.1988 \\ \mathbf{0 . 0 0 6} & 0.6036 & 0.9105 & 0.8361 & 0.7803 & 0.5943 & 1.0221 & 0.9849 & 1.4313 & 1.394 I & 1.6452 \\ \mathbf{0 . 0 0 8} & 0.7802 & 1.1058 & 1.0593 & 0.9662 & 0.7524 & 1.3569 & 1.2360 & 1.8218 & 1.8405 & 2.0544 \\ \mathbf{0 . 0 1 0} & 0.8547 & 1.3197 & 1.4127 & 1.1523 & 0.9291 & 1.7010 & 1.4871 & 2.2497 & 2.2404 & 2.3241 \\ \mathbf{0 . 0 2 0} & 1.3940 & 2.1938 & 2.0916 & 1.5986 & 1.4778 & 2.8262 & 2.3612 & 3.6726 & 4.3700 & 3.9702 \\ \mathbf{0 . 0 4 0} & 2.2684 & 3.0868 & 3.3284 & 2.4076 & 2.4544 & 3.9700 & 4.1656 & 6.4440 & 6.8532 & 5.4116 \\ \mathbf{0 . 0 6 0} & 2.6496 & 3.6540 & 3.9330 & 3.1890 & 3.2262 & 5.3928 & 5.2440 & 8.1828 & 7.6530 & 6.3138 \\ \mathbf{0 . 0 8 0} & 3.0216 & 4.2960 & 4.1656 & 3.7008 & 4.0072 & 6.3512 & 5.8952 & 9.2896 & 8.0992 & 7.2064 \\ \mathbf{0 . 1 0 0} & 3.2630 & 4.4540 & 4.2310 & 4.1840 & 4.2030 & 6.8900 & 6.4250 & 9.5220 & 8.6020 & 8.3500\end{array}$

Methanol 
Table Continued

\begin{tabular}{|c|c|c|c|c|c|c|c|c|c|c|}
\hline 0.000 & 0.0400 & 0.0400 & 0.0400 & 0.0400 & 0.0400 & 0.0400 & 0.0400 & 0.0400 & 0.0400 & 0.0400 \\
\hline 0.001 & 0.0558 & 0.4929 & 0.0837 & $0.065 I$ & 0.0372 & 0.0558 & 0.0465 & 0.8928 & 0.9951 & 0.7254 \\
\hline 0.002 & 0.2511 & 0.9021 & 0.4278 & 0.6045 & 0.5115 & 0.2465 & 0.5673 & 1.9158 & 1.9902 & 1.7112 \\
\hline 0.004 & 0.7719 & 1.7949 & 1.2369 & I.5066 & 1.4415 & 0.8928 & I.5252 & 3.8967 & $3.785 I$ & 3.5247 \\
\hline 0.006 & 1.2927 & 2.5854 & 1.9065 & 2.4924 & 2.2599 & $\mathrm{I} .4880$ & 2.5017 & 5.7195 & 5.7102 & 5.0406 \\
\hline 0.008 & $1.84 \mid 4$ & 3.3759 & 2.7528 & 3.3108 & 3.1713 & 2.0181 & 3.3945 & 7.6818 & 7.3842 & 6.0450 \\
\hline 0.010 & 2.2320 & 3.9339 & 3.3108 & 4.1943 & 4.3617 & 2.5017 & 4.6128 & 9.0954 & 8.7234 & 7.6167 \\
\hline 0.020 & 4.0827 & 7.5516 & 6.2589 & 8.0538 & 7.8492 & 4.0827 & 8.5002 & I5.9774 & 15.1404 & 12.6294 \\
\hline 0.040 & 6.5100 & $13.00 \mid 4$ & II.2344 & I 4.0244 & $13.00 \mid 4$ & 10.0347 & $13.93 \mid 4$ & 25.5564 & 24.9984 & 21.0924 \\
\hline 0.060 & 9.6813 & 19.1394 & I5.9774 & 19.2324 & I 7.7444 & 14.1174 & 19.3254 & 34.2984 & 33.8334 & 27.8814 \\
\hline 0.080 & 12.0807 & 23.0454 & 22.5804 & 23.7894 & 21.8364 & 18.0234 & 23.8824 & 42.6684 & 40.5294 & 33.8334 \\
\hline 0.100 & I 5.3264 & 27.9744 & 25.8354 & 25.9284 & 25.7424 & 24.4404 & 28.9044 & $49.27 \mid 4$ & 45.6444 & 38.3904 \\
\hline
\end{tabular}

[A]
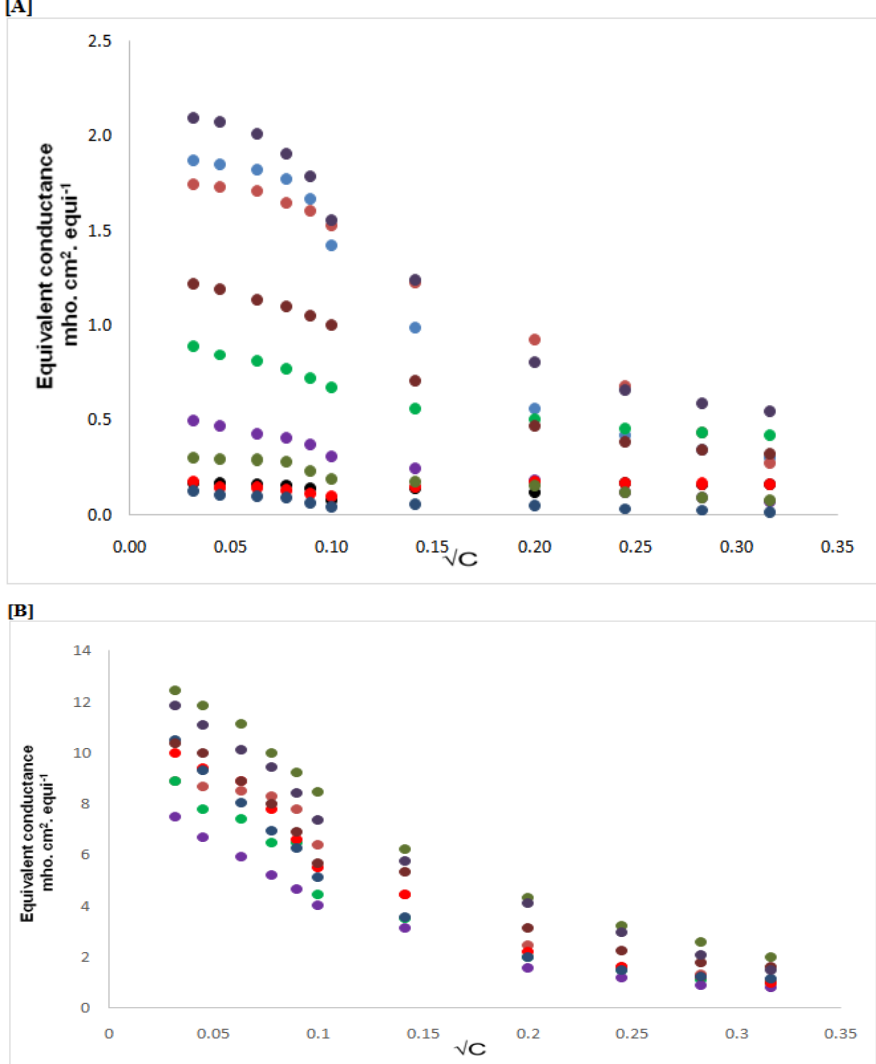

Figure 2 The variation of equivalent conductance with $\sqrt{ } \mathrm{C}$ for tetrahydropyrimidines in [A] DMF and [B] chloroform at $308.15 \mathrm{~K}$.

$\bullet: S N S-I ; \bullet: S N S-2 ; \bullet: S N S-3 ; \bullet: S N S-4 ; \bullet: S N S-5 ; \bullet: S N S-6 ; \bullet: S N S-7 \bullet: S N S-8 ;$ $\bullet:$ SNS-9; •: SNS-I0.

The equivalent conductance $\left(\lambda_{c}\right)$ is plotted against $\sqrt{ } \mathrm{C}$ for all compounds as shown in Figure 2-4. For tetrahydropyrimidine compounds, in DMF, equivalent conductance increases with concentration in both the solvents. At higher concentrations, the variation of equivalent conductance for different compounds is very less. Further, in DMF, equivalent conductance for tetrahydropyrimidine compounds are much lower than those in chloroform. It is obvious from Figure 2 that in DMF, most of tetrahydropyrimidine compounds behave as weak electrolytes whereas in chloroform, these compounds exhibited electrolytic behavior. For 2, 4-disubstituted pyrimidine compounds (both SDN and SDO compounds) also, equivalent conductance is less in DMF solutions than those in methanol solutions. Figure 3 shows that in DMF, SDN-2 and SDN-4 showed electrolytic behavior whereas for SDN-1, SDN-3 and SDN-5 compounds, equivalent conductance decreases at lower concentration. In methanol also, except SDN-2, for other four compounds also equivalent conductance decreases at lower concentration. Similar behavior was also observed for SDO compounds in both DMF and methanol solutions except SDO-3 in DMF (Figure 4). This typical behavior may be due to interactions within the molecule thereby causing constriction within the molecule or due to association between solute with solvent molecules. Similar behavior was observed by Singh et al. ${ }^{19,20}$

[A]
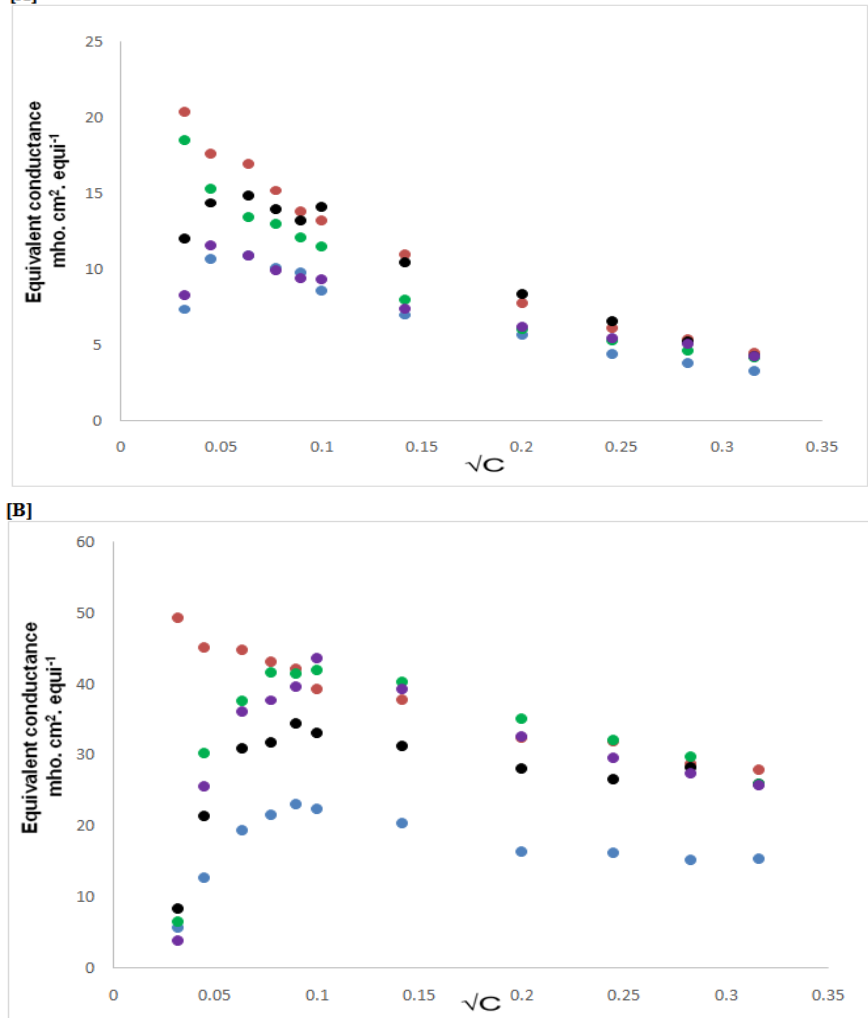

Figure 3 The variation of equivalent conductance with $\sqrt{ } \mathrm{C}$ for 2 , 4-disubstituted pyrimidines (SDN series) in [A] DMF and [B] Methanol at 308.15K.

$\bullet: S D N-I ; \bullet: S D N-2 ; \bullet: S D N-3 ; \bullet: S D N-4 ; \bullet: S D N-5$. 
[A]


Figure 4 The variation of equivalent conductance with $\sqrt{ } \mathrm{C}$ for 2 , 4-disubstituted pyrimidines (SDO series) in [A] DMF and [B] Methanol at 308.15K.

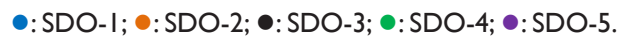

\section{Conclusion}

It is observed that physicochemical parameters of compounds in solution depends not only on the structure and substitution of the compound but also on the nature of solvent in which it is dissolved. The molecular interactions occurring in the solution affect volume which in turn causes a small change in density and refractive index. Depending upon the nature of solvent, the conductance i.e., electrolytic behavior of compounds also changes.

\section{Acknowledgements}

None.

\section{Conflict of interest}

The author declares that there is no conflict of interest.

\section{References}

1. Q Tu, M Eckelman, J Zimmerman. Meta-analysis and Harmonization of Life Cycle Assessment Studies for Algae Biofuels. Environ Sci Techn. 2017;51(17):9419-9432.

2. TH Chen, CF Chang, SC Yu, et al. Dipyridamole inhibits cobalt chlorideinduced osteopontin expression in NRK52E cells. Eur J Pharmaco. 2009;613(1-3):10-18.

3. CM Marson. Saturated Heterocycles with Applications in Medicinal Chemistry. Adv Heterocyc Chem. 2017;121:13-33.

4. ES Al-Abdullah, AR Al-Obaid, OA Al-Deeb, et al. Synthesis of novel 6-phenyl-2, 4-disubstituted pyrimidine-5-carbonitriles as potential antimicrobial agents. Eur J Med Chem. 2011;46(9):4642-4647.
5. PJ Manley, AE Balitza, MT Bilodeau, et al. 2, 4-Disubstituted pyrimidines: A novel class of KDR kinase inhibitors. Bioorg Med Chem Lett. 2003;13:1673-1677.

6. L Jing, Y Tang, M Goto, et al. SAR study on N 2, N 4-disubstituted pyrimidine-2, 4-diamines as effective CDK2/CDK9 inhibitors and antiproliferative agents. RSC advances. 2018;8(22):11871-11885.

7. G Luo, Z Tang, K Lao, et al. Structure-activity relationships of 2, 4 disubstituted pyrimidines as dual ER $\alpha /$ VEGFR-2 ligands with anti-breast cancer activity. European journal of medicinal chemistry. 2018;150:783795.

8. Z Czudor, M Balogh, P Bánhegyi, et al. Novel compounds with potent CDK9 inhibitory activity for the treatment of myeloma. Bioorganic \& medicinal chemistry letters. 2018;28(4):769-773.

9. MK Krapf, J Gallus, S Vahdati, et al. New Inhibitors of Breast Cancer Resistance Protein (ABCG2) Containing a 2, 4-Disubstituted Pyridopyrimidine Scaffold. Journal of medicinal chemistry. 2018;61(8):3389-3408.

10. T Mohamed, PP Rao. 2, 4-Disubstituted quinazolines as amyloid- $\beta$ aggregation inhibitors with dual cholinesterase inhibition and antioxidant properties: Development and structure-activity relationship (SAR) studies. European journal of medicinal chemistry. 2017;126:823-843.

11. J Jang, J Son, E Park, et al. Discovery of a Highly Potent and Broadly Effective EGFR and HER2 Exon 20 Insertion Mutant Inhibitor. Angew Chem Int Ed Engl. 2018;57(36):11629-11633.

12. A Sujayev, E Garibov, P Taslimi, et al. Synthesis of some tetrahydropyrimidine-5-carboxylates, determination of their metal chelating effects and inhibition profiles against acetylcholinesterase, butyrylcholinesterase and carbonic anhydrase. Journal of enzyme inhibition and medicinal chemistry. 2016;31(6):1531-1539.

13. M. Geramizadegan, G. H. Mahdavinia: cerium (iv) ammonium nitrate (can) as a catalyst in water: a simple, proficient and green approach for the synthesis of tetrahydropyrimidine quinolones. Journal of the Chilean Chemical Society. 2017;62:3578-3580.

14. S Sepehri, S Soleymani, R Zabihollahi, et al. Design, Synthesis, and AntiHIV-1 Evaluation of a Novel Series of 1, 2, 3, 4-Tetrahydropyrimidine -5-Carboxylic Acid Derivatives. Chem Biodivers. 2018;15:1700502.

15. P Taslimi, A Sujayev, F Turkan, et al. Synthesis and investigation of the conversion reactions of pyrimidine-thiones with nucleophilic reagent and evaluation of their acetylcholinesterase, carbonic anhydrase inhibition, and antioxidant activities. J Biochem Mol Toxicol. 2018;32(2):e22019.

16. BC Raju, RN Rao, P Suman, et al. Synthesis, structure-activity relationship of novel substituted 4H-chromen-1, 2, 3, 4-tetrahydropyrimidine-5carboxylates as potential anti-mycobacterial and anticancer agents. Bioorg Med Chem Lett. 2011;21:2855-2859.

17. JA Riddick, WB Bunger, T Sakano. Organic Solvents: Physical Properties and methods of purification. 4th edition. Techniques of Chemistry II, A Wiley-Interscience Publication: New York; 1986.

18. GL Slonimskii, AA Askadshii, AI Kitaigorodskii. The packing of polymer molecules. Polymer Science U.S.S.R. 1970;12(3):494-498.

19. M Singh, A Kumar, S Easo, et al. Electrolytic conductivity of crystal violet based quaternary ammonium polyelectrolytes in dimethylformamide and dimethyl sulfoxide. Can J Chem. 1997;75:414-422.

20. M Singh, BB Prasad. Electrolytic conductivity of the N-chloranil- and $\mathrm{N}$-xylylene- based polyelectrolytes in dimethylformamide and dimethyl sulfoxide. J Chem Eng Data. 1996;41(3):409. 